\title{
Cultivating Intercultural Communication Competence through Culture Teaching
}

\author{
Jiao Xue \\ Zhenjiang Watercraft College, China
}

\begin{abstract}
Applied linguists and language teachers have been increasingly aware that a second or foreign language can hardly be acquired or learned without addressing the culture of the community in which it is spoken. A second language learner's understanding of a second culture is fundamentally affected by his or her culturally-defined world of view, beliefs, and presuppositions. The beliefs and presuppositions have important pedagogical implications and need to be considered in second or foreign language teaching and learning. In cross-cultural communication, linguistic knowledge alone is not enough in guaranteeing successful interaction with native speakers. Cultural mistakes are worse than linguistic ones because they tend to create misjudgment, or ill feeling between native and foreign speakers. EFL teachers should stress the cultivating of learners' cross-cultural awareness while they pass on linguistic knowledge. The study of communicative competence has received more and more attention in the field of English learning and teaching, and a great deal has been discovered about the culture teaching and communicative competence. I take these findings as a starting point and develop the discussion in the context of English teaching and learning in China. Accordingly, my discussion in the thesis aims to bring together some of the varied facets of the whole picture for the reader and present a brief analysis of how to cultivate learners' communicative competence through cultural teaching.
\end{abstract}

Index Terms - language, culture, culture teaching, intercultural communication competence

\section{INTRODUCTION}

Nowadays, almost all the countries in the world have a close relationship with each other. With the development of economic globalization, English is becoming more and more important and is now the world's most widespread language existing and functioning as a world language. It functions as an international communication too. Nowadays, almost all the countries in the world have a close relationship with each other. With the development of economic globalization, English is becoming more and more important and is now the world's most widespread language existing and functioning as a world language. It functions as an international communication tool. Therefore, it does not work well if we are just acquainted with its grammar and vocabulary. It is essential to know the cultural background because it is well known that language and culture are inseparable from each other. When we study English, we will not only develop language skills, that is, the competence in listening, speaking, reading and writing, but try to understand the significance of behaviors, values and other cultural background of the English-speaking countries as well. Because any language is part of a certain culture, the acquisition of a foreign language is also the acquisition of a foreign culture. (Jiang, 2003)

The aim of this thesis is to make a study of cultural teaching of the college students in order to find out whether it is feasible to cultivate college learners' intercultural communication competence through cultural teaching and offer some suggestions for incorporating culture into language teaching.

\section{THEORETICAL FOUNDATION OF THIS THESIS}

\section{A. Language, Culture, and Communication}

The cultivation of ICC competence is based on the inseparable relationship among language, culture and communication. To give theoretical support to the thesis, this chapter will undertake the exploration of the nature and relationship of language, culture and communication. Additionally, the definition of intercultural communication competence is introduced.

1. Language and Culture

Both language and culture are so elusive and complex that defining them is not an easy job at all. With about 500 definitions of language, it seems that there are as many definitions as there are scholars. Thus a unanimous definition of language and culture is simply out of the question and also unnecessary. Instead of attempting to add to a list of definitions of the both, this section draws upon the definition proposed so far and describes the general nature of each. It is hoped that this general description of language and culture will serve as the conceptual basis on which this thesis will operate throughout.

a. Defining Language

Language is considered to be a system of communicating with other people using sounds, symbols and words in 
expressing a meaning, idea or thought. Language can be used in many forms, primarily through oral and written communications as well as using expressions through body language. Modern linguists have proposed various definitions of language, some of which are quoted below:

"Language is a purely human and non-instinctive method of communicating ideas, emotion and desires by means of voluntarily produced symbols."(Sapir, 1921, p.221)

Language is" the institution whereby humans communicate and interact with each other by means of habitually used oral-auditory arbitrary symbols."(Hall, 1968, p.158)

"From now on I will consider language to be a set (finite or infinite)of sentences, each finite in length and constructed out of a finite set of elements."(Chomsky, 1957, p.26)

Each of these definitions has its own special emphasis, and is not totally free from limitations. However, there are some important characteristics of human language that linguists have agreed on; these are embraced in the following generally accepted definition:

Language is a system of arbitrary, vocal symbols used for human communication. Short as it is, this definition has captured the main features of language.

First of all, language is a system, i.e., elements of language are combined according to rules

Secondly, language is arbitrary in the sense that there is no intrinsic connection between a linguistic symbol and what the symbol stands for. The fact that different languages have different words for the same object is a good illustration of the arbitrary nature of language. This also explains the symbolic nature of language: words are just symbols; they are associated with objects, actions and ideas by convention.

Thirdly, language is vocal because the primary medium for all language is sound. All evidence points to the fact that writing systems came into being much later than the spoken forms and that they are only attempts to capture sounds and meaning on paper.

Finally, the term "human" in the definition is meant to specify that language is human-specific, i.e., it is distinguished from means of communicating which other forms of life may possess.

b. Defining Culture

It is known that culture is ubiquitous, multidimensional, and complex. The term culture has been defined by many researchers and scholars from their own points of view. E.B.Tylor (1920, p.9), a nineteenth-century anthropologist, first defined culture as" that complex whole which includes knowledge, belief, art, morals, law, custom, and any other capabilities and habits by man as a member of a society". In 1925, A.L.Kroeber and Kluckhohn listed 164 definitions of culture that they found in the anthropology literature (Samovar \& Porter, 1994, p.47).Since then, more different definitions have appeared.

Since our goal is to understand the interaction between people from different cultural backgrounds, we will adopt the anthropological view of culture in our study of ICC competence. A simple definition offered by Ferraro (1995) well serves our purpose. He defines culture as" everything that people have, think, and do as members of a society." We take this as a working definition because it is both instructive and inclusive; it covers all of the three components of culture: material objects, belief systems, and behavior patterns. According to Ferraro, everything that people think refers to what people have in their mind; what people have refers to their material possessions; and what people do refers to their behavioral patterns.

c. The relationship Between Language and Culture

The relationship between culture and language has been studied by many scholars (such as Byram, Brown and Malinowski) and different opinions about it have been put forward. In spite of different perspectives on the relationship between culture and language, it has been widely accepted that language and culture are inextricably linked to one another.

On the one hand, Language is an integral part of a culture and plays a very important role in it. Language influences culture by affecting perception and thought patterns and by helping to categorize cultural information and people's ideas.

On the other hand, language is influenced and shaped by culture; it reflects culture.

Language structure, communication patterns, rhetoric rules, etc. are influenced or ever restricted to a large degree by its superstructure - culture.

The relationship between culture and language can be clearly revealed in the powerful argument made by Malinowski (1944, p.305) that an understanding of a language is impossible without constantly relating it to the culture in which it is operative. The intimate link of language and culture implies that learning a foreign language is inseparable from learning its culture. Byram (1989, p.22) stated, "as learners learn about language they learn about culture and as they learn to use a new language, they learn to use a new culture". Therefore, it is of great necessity to teach language and culture simultaneously in foreign language teaching. If we teach language without teaching, at the same time, that culture in which the language operates, we are teaching meaningless symbols or symbols to which the students attaches the wrong meaning.

To sum up, language and culture are inseparably interwoven.

2. Culture and Communication

Culture and communication, two different concepts, are directly linked to each other. They are so inextricably bound 
that some anthropologists believe these two terms are virtually synonymous. Smith (1996) noted "Whenever people interact they communicate. To live in societies and to maintain their culture, they have to communicate." And just as Hall reminds us," culture is communication and communication is culture. "Culture is learned, transmitted and preserved through communication. Communication and culture are inseparable.

Since culture is defined succinctly as" the totality of beliefs and practices of a society," nothing is of greater strategic importance than the language through which its beliefs are expressed and transmitted and by which most interaction of its members takes place.

Before we turn to elements of culture, it is important to understand the overall reasons why culture influences communication.

First of all, each culture encourages a particular communication style expected within each culture. A specific culture expects an "ideal" communication style. The contrasts are striking. For instance, an American speaking in a "normal" conversational voice seems loud to a "quiet" Thai national, who interprets the American to be angry. This case illustrates the ideal cultural communication styles in conflict, a conflict rooted in each culture's communication expectations.

In addition, culture has the power to shape perception. However you describe it, culture shapes perception by exercising the human tendency to categorize others. These stereotypes engendered are not always accurate but they persist as powerful images, feelings, and beliefs our culture impresses.

In sum, culture is something like glue that bonds people together. There are some tendencies that typify some group members and areas where individual differences persist.

\section{B. ICC Competence and Its Components}

Studies on intercultural communicative competence were driven by practical needs such as sending personnel abroad to perform political and commercial tasks in the early 1960s. The notion of intercultural communicative competence has been proposed as one of the main goals of English teaching since the late 1970s. With increasing intercultural communication, intercultural communicative competence has been studied by sociologists, psychologists, sociolinguists, etc. and a considerable amount of literature was produced. To enhance intercultural communicative competence, it is necessary to know what intercultural communicative competence means and what its components are.

1. Defining ICC Competence

Intercultural communicative competence has defined by many researchers in a variety of ways. It has been investigated under different labels, such as cross-cultural adjustment, intercultural understanding, intercultural effectiveness, cross-cultural awareness (Guthrie \& Zektick, 1967; Harris, 1975; Ruben \& Kealy, 1979; Spizberg \& Cupach, 1984). In the past two decades, there has been a growing consensus on the conceptualization of ICC competence. Many scholars agree that appropriateness and effectiveness are key words to define ICC competence. Spitzberg (2000, p.259) defines ICC as "an impression that a behavior is appropriate and effective in a given context".

According to Chen and Starosta (1998), intercultural communication competence is defined as" the ability to effectively and appropriately execute communication behaviors to elicit a desired response in a specific environment". Similarly, Rogers and Steinfatt define ICC as the degree to which an individual is able to exchange information effectively and appropriately with individuals who are culturally unlike others. Therefore, with these dual standards, communicator will be competent in an intercultural context when the desired objectives are fulfilled in a manner that is appropriate to the context and relationship.

In general, researchers have studied the concept of ICC from three approaches: cross-cultural attitude approach, behavior-skill approach and developmental approach.

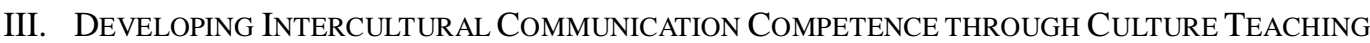

From the previous parts, it can be seen that language and culture are inseparable. Therefore, language teaching is, in a sense, can not go without cultural teaching.

\section{A. The Aims of Culture Teaching}

Based on the theories of the above chapters, we suggest the following culture aims established by Tomolin and Steemplesik (1993, p.8) with Chinese context of foreign language teaching in view:

1. To help students to develop an understanding of the fact that all people exhibit culturally-conditioned behaviors.

2. To help students to become more aware of conventional behavior in common situations in the target culture.

3. To help students to increase their awareness of the cultural connotations of the words and phrases in the target culture.

4. To help students to develop an understanding that social variables such as age, sex, social class, and place of residence influence the way in which people speak and behave.

5. To help students to develop the ability to evaluate and refine generalizations about the target culture, in terms of supporting evidence.

6. To stimulate students' intellectual curiosity about target culture, and to encourage empathy toward its people.

7. To help students to develop the necessary skills to locate and organize information about the target culture 


\section{B. The Principles of Culture Teaching}

Teachers should follow the following cultural teaching principles for the development of students' intercultural communication competence in the teaching activities:

1) Use target language as the primary vehicle to teach culture

We have discussed in the previous chapters that language is inseparable from culture and language is the most important symbolic representation of a culture. Therefore, of all the elements of the target culture, the target language is the most typical, the most unique and the most readily available. Its authentic use in the classroom from the beginning of instruction is the primary cultural objective. Teachers can create a classroom cultural environment for the learners by using the target language.

2) Prevent the negative effects of native culture on target culture teaching

Cultural teaching is affected not only by native language but also by the native culture. The learners will always attach the contents and meanings of the native culture on the target culture unconsciously because of the vast differences between the native culture and target culture. This will severely affect the accuracy of the understanding and expressing. This kind of phenomenon is called negative effects of native culture on communication. Therefore, we must prevent this kind of negative effects. The effective measures we can take are as follows: firstly, related cultural knowledge is necessary to be taught; secondly, the explanation of the related cultural knowledge should be fulfilled through the comparison and contrast between the native culture and target culture especially when we teach a new word with special cultural background. Besides the definition of the word, cultural background must be explained clearly in order to avoid misuse of the word.

3) Suitable level of difficulty

The teachers should always keep in mind what level their students are at. It is important to know about the students. If the material is too easy, the learners will not have the desire to go on with the learning and otherwise if the content is of extreme difficulty, the learners will lose their confidence and interest in learning. Suitable level of difficulty is of great importance in the cultural teaching.

4) Limited cultural coverage

As we have showed in the above chapter that a culture is a unity of history, beliefs, values, cultural activities and so on, so a culture is enormous. It is neither realistic nor necessary for us to teach and learn all the aspects of a culture. Therefore, we can not cover everything of the culture. What we should focus on are the elements which would influence our cultural teaching and the most important is that we should 30 cultivate the communicative competence through cultural teaching.

5) Employ cultural comparison method

Culture plays an instrumental role in shaping speakers' communicative competence, which is related to the appropriate use of language (e.g. how native speakers make an apology and what kind of form the apology is to take).Generally, appropriateness is determined by each speech community .In other words, it is defined by the shared social and cultural conventions of a particular group of speakers.

Therefore, it is essential to recognize different sets of culturally determined rules in communication. Teachers can present situation in which there is cultural misunderstanding that causes people to become offended, angry, and confused. Then, thought-provoking information and questions can follow each description or anecdote for in-class discussion. Learners can be asked to analyze and determine what went wrong and why, which will force learners to think about how people in the target culture act and perceive things, and which will inevitable provide a deeper insight into that culture.(Kang, 1997)

This kind of exercise can strike a healthy balance between the necessity of teaching the target culture and validating the learners' native culture, which will gradually sharpen learners' culture awareness, thus improving people's intercultural communication competence.

\section{The Strategies of Culture Teaching}

The main purpose of cultural teaching which aims at enhancing the learners' communicative competence is to produce certain language forms in an acceptable way.

The learners are generally prompted to use these forms by the teacher's instructions (as in a drill).Alternatively, the teacher may have not designed the activity so as to provide an opportunity for learners to produce language that they have recently learnt (e.g. through open or cued dialogues). The teacher's overall purpose is to prepare the students with the necessary linguistic forms and the necessary links between forms and meanings. Based on this theory, the strategies of cultural teaching should be as follows:

1) Arouse learners' interest in cultural teaching

It goes without saying that interest is the best teacher. But we have to admit that because of the constraints of CET-4 on the English teaching, the Chinese college students attach excessive importance on the study of linguistic competence but often ignore the importance of cultural teaching. Few of them have a strong interest in cultural teaching and learning. Therefore, the first step to conduct cultural teaching is to arouse their interest and widen their insight into this language and its culture.

2) Set cultural context for vocabulary

There are abundant culture-loaded words in English. Chinese learners often understand these words according to the 
native culture. The result is that they are often confused about these words, make mistakes using them or even confronted with culture shock. For example, many Chinese learners understand "adult books" as the books for adults. In fact, if we reveal the cultural connotation of the word, we know that it is the euphemism for pornographic books. Learning new words with the help of cultural knowledge is the solution for creating cultural contest for vocabulary. In our English teaching and learning we find that lack of cultural knowledge is a key barrier to the understanding of an article. Therefore, teaching and learning pronunciation, words and grammar merely is not sufficient in our study task. We have to cultivate learners' cultural awareness to help them study and understand the language of another culture.

3) Create a cultural context for teaching activities

Chinese learners tend to have an over-reliance on the native language, which is not beneficial for the teaching activities to be carried out. The classroom atmosphere is a vital element influencing learners' activities. It is necessary to create a suitable atmosphere that would allow learners to express themselves freely and make them feel eager to communicate in the foreign language. Interactive activities should be based on authentic or naturalistic source material.

4) Select and arrange the teaching content properly

Researchers have put forward such principles for the selection and arrangement of teaching content.

a. Need-based foreign language teaching

The aim of needs analysis is to determine the type of situation in which learners will be using English, the English tasks and activities they are expected to carry out or take part in, and their existing language abilities with respect to those tasks. In order to define the need of a group of learners, the situations in which they will need the foreign language must first be specified. For example, the specification of a situation concerning the register means stating the settings, the roles a language user has to play, and the topics to be dealt with. Communicative activities and topics can be selected in which all learners should take part to organize foreign language teaching.

b. The notion of authenticity

One way to enable learners to be competent in communication is to experience the target language in real situations. But how do teachers set about devising procedures which will bring about? Since our aim is to enable them to produce and process actual language use, then, the answer is that learners should be exposed to authentic language material. According to Widdowson (1999), the authenticity has to do with appropriateness, which is the interpretation by reference to the accepted rules, linguistically and socially, which are associated with a particular register. As a result, learners will become actively involved as participants in authentic language use. Teachers take the responsibilities to prepare teaching material to the point where the learners are capable of responding to the genuine discourse they have selected in authentic fashion. Learners should be guided to an awareness of the communicative rules operating in the kind of register they will be concerned with. When teaching "invitation", for example, the teacher not only deals with inviting, but also accepting and declining an invitation. What is provided is a set of semantic options for the network of invitation. Once this is provided, practical selections from real life can be implemented: Learner A can invite(selecting from the various exponents provided), and Learner B can select whether to accept or decline(again choosing from various exponents, and at the same time his exponent is situationally appropriate to the exponent of invitation he or she hears).It will be the material producer's task to provide techniques by which this process of selection can be meaningful. For example, it can be related to a created context by providing realia, such as a diary in which the learner fills in appointments. The learner then accepts invitation at times when he or she is free and declines when he or she is not.

2. The Contents of Culture Teaching

Based on the above principles and strategies, cultural teaching in English classes shall accommodate the following contents:

1) Cultural connotation of words

Words are the most basic elements of a language and vocabulary is a mirror of language. Therefore, cultural teaching should first of all focus on the teaching and earning of the cultural connotation of words like the demonstrative category, affective meaning and associative meaning of words, and the application of the usage for them which embody cultural backgrounds. For example, "breakfast "seems to be a simple word, but in fact the breakfast for the Chinese people is quite different from the breakfast for the Western people. A contrast between the Chinese breakfast and Western breakfast is, therefore, needed to create a cultural environment for the learners.

2) Expressions and idioms with distinct target culture features

There are abundant expressions and idioms with distinct target culture features in a foreign language. Learning these expressions and idioms is a vital task for us. For example, Britain is a country with a lot of islands and some idioms are in a close connection with water. "over head and ears" was created by the sailors, which means"the water inundates the head and ears". Later this idiom became popular and was used on many other occasions. And a lot of expressions with it are formed such as"over head and ears in debt", over head and ears in love", and so on.

3) Cultural factors affecting verbal and nonverbal communication

Verbal communications and nonverbal communications are greatly affected by cultural factors. The former includes the standard functions of greetings, thanks, apologies, farewells, phone calls, requests, and invitations, choice of topics, euphemisms, social conventions and etiquettes. The latter refers to gestures, body motions, customs, and varying attitudes towards time and space.

4) General knowledge of the English-speaking countries 
Even though the college learners have studied English for about eight years, some of them still cannot speak out the full name of the country-Britain. This reveals that learning a language cannot be isolated from the learning of the history of that country. In other words, the teaching and learning of the cultural background information in the classroom teaching is quite important and necessary, which is of great help in cultivating learners' cultural awareness and therefore becomes the basis of improving their communicative competence.

5) Differences in cultural values and thinking patterns

The Chinese people and Western people hold quite different cultural values and therefore they have formed different thinking patterns. This aspect exerts an important influence on the writing task. For example, a Chinese teacher has done a survey in a college. When the students are required to write an article with the title" Turn off the TV for an Hour", most Chinese college students begin the article with such a sentence"With the development of the society, more and more households in China possess a TV set". But the Western people prefer to begin the article directly with such a sentence "I suggest turn off the TV for an hour because of the following reasons". The difference of cultural values and thinking patterns will influence communication severely and therefore is an important cultural teaching content

\section{CONCLUSION}

The learning and teaching of a foreign language is a complex process, involving seemingly infinite number of variables. The intricate web of these variables that are pun together influences language learning as well as teaching. Rather than yielding to the temptation of making a quick, haphazard choice of a stance, it is necessary to scrutinize many variables and relationships that come to bear on foreign language teaching.

Generally speaking, language teaching is known as one of the most important aspects in applied linguistics, and at present, communicative language teaching (CLT) is widely adopted by the foreign language teachers, especially English teachers, in China. It is well admitted that the purpose of language learning is to use it for communication. Therefore, the fundamental task for language teaching is improving learner's communicative competence.

The original idea of communicative competence is that speakers of a language have to have more than grammatical competence in order to be able to communicate effectively in a language; they also need to know how language is used by members of a speech community to accomplish their purposes. Communicative competence has its own background, that is to say, communication always occurs on a certain occasion. And a qualified communicator should choose a proper language to express himself according to the variation of the occasion, which requires that the learners should get to know and master the communicative strategies, which are useful to improve their communicative competence.

This thesis has conducted a study of the effects of cultural teaching on the development of intercultural communication competence thourough theories and suggests some teaching methods and teaching materials. Through the analysis, we can conclude that cultural teaching is an appropriate and feasible way to develop college students' intercultural communication competence.

\section{REFERENCES}

[1] Byram, M. (1989). Cultural Studies in Foreign Language Education. Clevedon, Avon: Multilingual Matters.

[2] Brumfit, C.J .\& Johnson,K. (1999). The Communicative Approach to Language Teaching. Shanghai: Shanghai Foreign Education Press.

[3] Brown,H.D. (2002). Principles of Language Learning and Teaching. Beijing: Foreign Language Teaching And Research Press.

[4] Canale,M.,and M.Swain.(1980).Theoretical Bases of Communicative Approaches to Second Language Teaching and Testing. Applied Linguistics.

[5] Chomsky,N.(1996).Aspects of the Theory of Syntax. Cambridge: MIT Press.

[6] Dodd,C.H.(2006).Dynamics of Intercultural Communication. Shanghai: Shanghai Foreign Education Press.

[7] Davis,L.(2001).Doing Culture: Cross-cultural Communication in Action. Beijing: Foreign Language Teaching And Research Press.

[8] Ferraro, G.. (1995). Cultural Anthropology. St. Paul, MN: West Publishing Company.

[9] Fiere,P. (1973). Pedagogy for Critical Consciousness. New York: Seabury Press.

[10] Hall,J.K..(2005).Teaching and Researching Language and Culture. Beijing: Foreign Language Teaching And Research Press.

[11] Haviland,W.A. (1975). Cultural Anthropology. New York: Holt, Rinehart and Winston.

[12] Jiang Xiaohong (2003). Developing Intercultural Communicative competence. Shanghai: Shanghai Foreign Education Press.

[13] Kang Shumin(1997). Factors to Consider Developing Adult EFL Students' Speaking Abilities. Shanghai: Shanghai Foreign Education Press.

[14] Littlewood,W. (2000). Communicative Language Teaching. Beijing: Foreign Language Teaching And Research Press.

[15] Leech G N. (1983). Principles of Pragmatics. London: Longman.

[16] Malinowski, B. (1944). A Scientific Theory of Culture and Others Essays. Chapel Hill, N. Carolina: The University of North Carolina Press.

[17] Moran,P.R.(2004).Teaching Culture-Perspectives in Practice. Beijing: Foreign Language Teaching And Research Press.

[18] Reid,J.M.(2002). Learning Styles in the ESL/EFL Classroom, Beijing: Foreign Language Teaching And Research Press.

[19] Sapir .E. (1921). Language: An Introduction to Study of Speech. New York: Harhcount, Brance \& Company.

[20] Tylor, Edward. (1920). Primitive Culture. New York: J. P. Putnam’s Sons..

[21] Weaver,G.R. (1993). Understanding and coping with cross-cultural stress. Yarmouth, ME: Intercultural Press.

[22] Widdowson,H.G. (1999) Teaching Language as Communication. Shanghai: Shanghai Foreign Education Press. 
Jiao Xue was born in Yangzhou, China in 1986. she received her M.A degree in foreign linguistics and applied linguistics from Jiangsu University of Science and Technology, China in 2011.

She is currently a tutor in English Department, Zhenjiang Watercraft College, Zhenjiang, China. Her research interests include second language acquisition and intercultural communication. 